\title{
CDISC SDTM Administration Technique Response Terminology
}

National Cancer Institute

\section{Source}

National Cancer Institute. CDISC SDTM Administration Technique Response

Terminology. NCl Thesaurus. Code C132311.

Terminology associated with the administration technique response codelist of the Clinical Data Interchange Standards Consortium (CDISC) Study Data Tabulation Model (SDTM). 